\title{
Can't We All Just Get Along? Improving the Law Enforcement- Intelligence Community Relationship
}

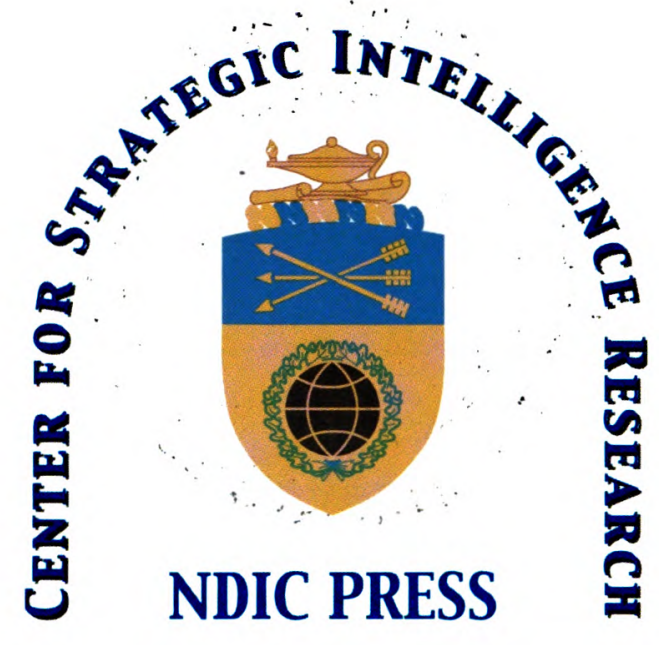
National Defense Intelligence College
Washington, DC
June 2007

The views expressed in this book are those of the authors and do not reflect the official policy or position of the Department of Defense of the U.S. Government 